\title{
Current issues and perspectives in PD-1 blockade cancer immunotherapy
}

\author{
Kenji Chamoto $^{1} \cdot$ Ryusuke Hatae $^{1} \cdot$ Tasuku Honjo $^{1}$
}

Received: 24 May 2019 / Accepted: 14 November 2019 / Published online: 3 January 2020

(c) The Author(s) 2019

\begin{abstract}
Programmed cell death 1 (PD-1) signal receptor blockade has revolutionized the field of cancer therapy. Despite their considerable potential for treating certain cancers, drugs targeting PD-1 still present two main drawbacks: the substantial number of unresponsive patients and/or patients showing recurrences, and side effects associated with the autoimmune response. These drawbacks highlight the need for further investigation of the mechanisms underlying the therapeutic effects, as well as the need to develop novel biomarkers to predict the lack of treatment response and to monitor potential adverse events. Combination therapy is a promising approach to improve the efficacy of PD-1 blockade therapy. Considering the increasing number of patients with cancer worldwide, solving the above issues is central to the field of cancer immunotherapy. In this review, we discuss these issues and clinical perspectives associated with PD-1 blockade cancer immunotherapy.
\end{abstract}

Keywords Immune checkpoint inhibitor $\cdot$ Biomarker $\cdot$ Immune-related adverse event $\cdot$ Immune metabolism $\cdot$ Combination therapy

\section{History of cancer immunology: basic to clinical research}

The hypothesis that most cancer cells are eliminated by the host immune system during cancer development is known as "immunological surveillance"; this concept was proposed by Burnet in the 1960s. However, this theory failed to explain the reasons for cancer proliferation despite immunological surveillance. In 2002, Dunn et al. referred to "cancer immunoediting", which comprises three stages: the "elimination phase", "equilibrium phase", and "escape phase" [1]. In the elimination phase, abnormally proliferating cells are eliminated via immunological surveillance. Abnormally proliferating cells that are not eliminated enter the precancerous, equilibrium phase in which apparent tumor size remains unchanged, as the rate of elimination by immune cells is

Kenji Chamoto and Ryusuke Hatae contributed equally to this work

Tasuku Honjo

honjo@mfour.med.kyoto-u.ac.jp

1 Department of Immunology and Genomic Medicine, Kyoto University Graduate School of Medicine, Yoshida Konoe-cho, Sakyo-ku, Kyoto 606-8501, Japan equal to the proliferation rate of abnormal cells. However, once abnormal cells have acquired mechanisms that allow them to escape immunological surveillance, they enter the escape phase, where a growing mass is recognized as cancer. Anti-tumor immunity involves various immune cells, but the final effector cells are cytotoxic T lymphocytes (CTLs), which specifically recognize and kill diverse antigens expressed on cancer cells. Cancer immune escape involves the loss of tumor antigen, human leukocyte antigen (HLA), and expression of immunosuppressive molecules in tumor cells, as well as induction of immunosuppressive cells.

Programmed cell death 1 (PD-1) is an immunosuppressive co-stimulatory signal receptor that belongs to the CD28 family. PD-1 was first identified by Ishida et al. in 1992 as a programmed cell death-induced gene encoding type I membrane proteins in T cells (Fig. 1) [2]. PD-1 was shown to be an immune suppressive factor based on the development of autoimmune diseases in PD-1 receptor-deficient mice [3-6]. PD-1 is expressed primarily on activated $\mathrm{T}$ cells and $\mathrm{B}$ cells, and serve as an immune regulator that controls inappropriate and extreme immune responses such as autoimmune and excessive infectious immune responses. It suppresses antigen receptor activation by PD-ligand 1 (PD-L1) and PD-L2, which belong to the co-stimulatory signal B7 family. Although PD-L1 


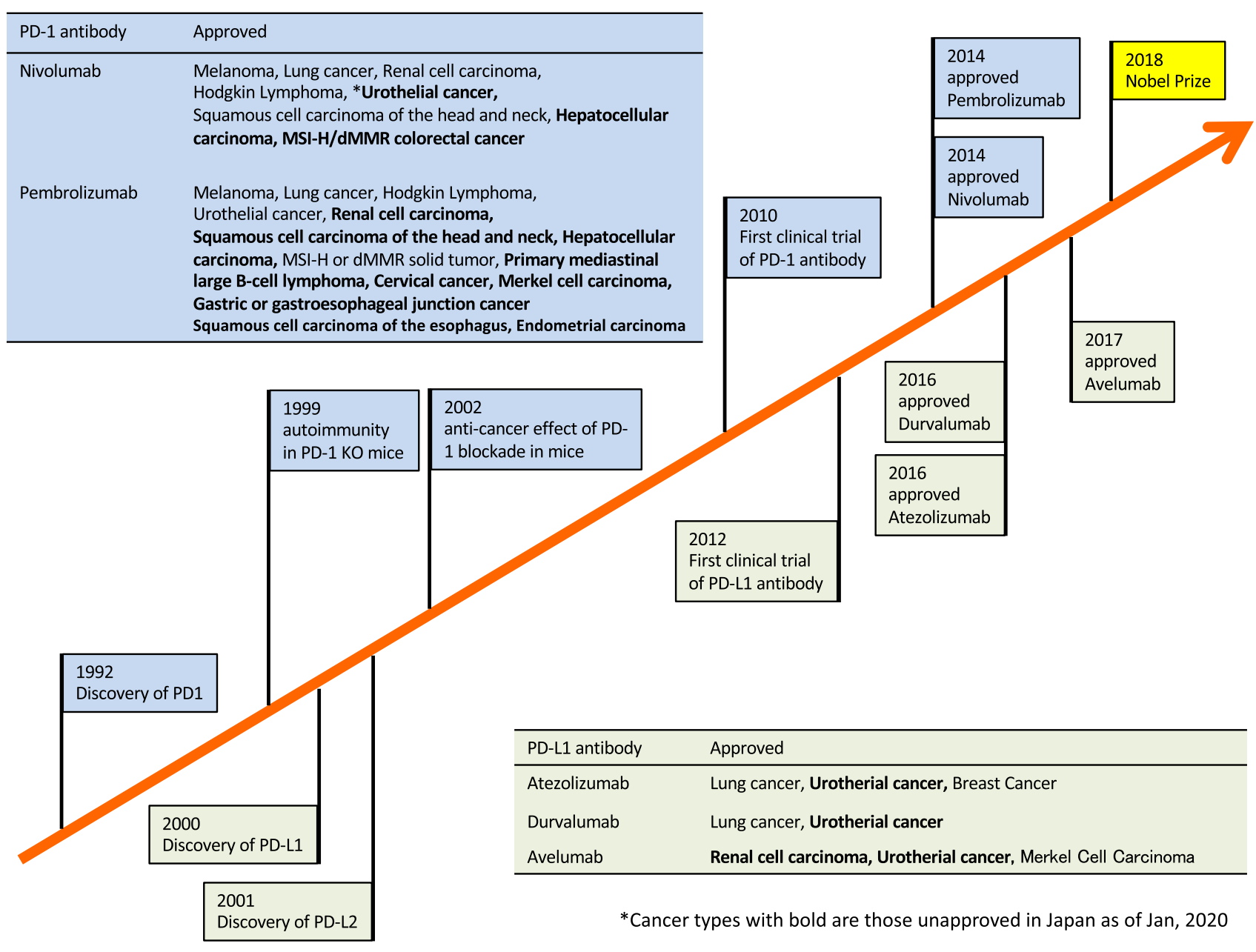

Fig. 1 History of programmed cell death-1 (PD-1) blockade cancer immunotherapy development

is widely expressed on antigen-presenting cells (dendritic cells, blood vessels, myocardium, lung, and placenta), PD-L2 is present on dendritic cells and is only expressed in activated macrophages. Binding of PD- 1 to PD-L1/2 is primarily related to immunosuppression in the peripheral tissue. Indeed, PD-L1-introduced tumors grow quickly in wild-type mice but not in PD-1-knockout mice, indicating that PD-1 plays a central role in cancer cell immune escape mechanisms [7]. Based on the hypothesis that interruption of anti-PD-1/PD-L1 binding may activate $\mathrm{T}$ cells against cancer cells, PD-1 blocking antibodies have been developed as immune checkpoint inhibitors for cancer therapy [7] (Fig. 1).

The clinical efficacy of nivolumab, an antibody against human PD-1, was subsequently reported in 2010 and 2012 $[8,9]$. In 2014, nivolumab was approved in Japan for the treatment of malignant melanoma for the first time worldwide. PD-1/PD-L1 antibody-based therapy is currently approved for the treatment of various cancers (Fig. 1).
However, more than half of patients do not respond to this therapy [10].

Improving the response rate in patients with cancer relies on three different approaches: (1) elucidating the mechanisms underlying the lack of response to PD-1 antibody treatment, (2) developing novel predictive markers, and (3) developing an effective combination therapy. These approaches and the status of current research are discussed in the subsequent sections.

\section{Biomarkers}

Killer $\mathrm{T}$ cells are the final effector immune cells that attack cancer cells. Killer T cell activity cannot be predicted by any single biomarker as it is controlled by various factors (Fig. 2), including tumor- and immune-related factors, as well as environmental factors such as enterobacteria and metabolism. 
Fig. 2 Regulation of killer T cell activity by various factors during PD-1 blockade therapy
External/internal environment

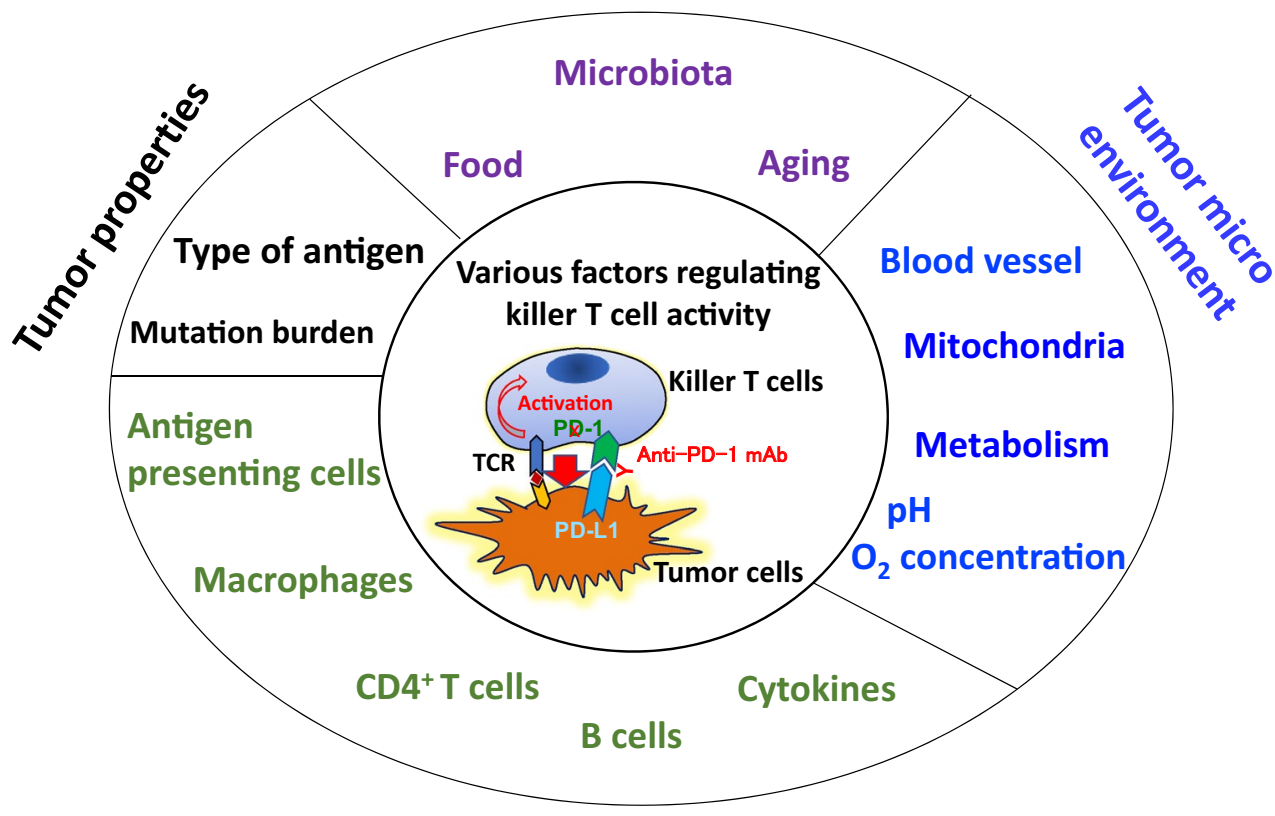

Immune properties

\section{Biomarkers-tumor-related factors}

A nivolumab phase I clinical study revealed that PD-L1 expression in tumor cells may be an indicator of treatment efficacy [8]. Several clinical trials subsequently evaluated whether PD-L1 expression could be a predictive biomarker. However, a significant association between improved outcomes and PD-L1 expression was observed only in certain cancers [11]. According to clinical studies showing a positive association, the United States (US) Food and Drug Administration (FDA) approved pembrolizumab for the treatment of PD-L1-positive non-small cell lung cancer (NSCLC), gastric or gastroesophageal junction cancer, and cervical cancer in 2015, 2017, and 2018, respectively. Furthermore, considering IMpassion130 study results, the FDA approved therapy with atezolizumab (a PD-L1 antibody) and chemotherapy (nab-paclitaxel) for PD-L1-positive and metastatic triple-negative breast cancer (TNBC) in March 2019 [12].

Two main mechanisms are hypothesized to be involved in PD-L1 expression in tumors: forced expression of PD-L1 due to translocations or mutations [13], and stimulation of intra-tumoral $\mathrm{T}$ cell-produced interferon, also known as "adaptive resistance" [14-16]. Because adaptive resistance is regulated by immune cell activity, PD-L1 expression show a correlation with PD-1 blockade therapy prognosis. However, insufficiency of tumor PD-L1 expression as a biomarker may result from difficulties in distinguishing the above two mechanisms. Moreover, PD-1/PD-L1 expression in tumor-infiltrating immune cells ( $T$ cells and macrophages) is reported to be involved in the therapeutic effects in malignant melanoma or bladder cancer [15, 17-19].

PD-1 antibodies are effective for tumors with somatic mutations, such as malignant melanoma, lung cancer, and renal cell carcinoma (RCC) [20]. Tumor-infiltrating T cells recognize mutated peptides as foreign antigens (neoantigens), thus inducing a strong immune response. Rizvi et al. demonstrated a significant correlation between therapeutic effect and neoantigen number, DNA repair pathway mutations, and non-synonymous mutations in pembrolizumabtreated patients with NSCLC [21]. In the CheckMate 026 study (phase III), which used nivolumab as first-line NSCLC treatment, high tumor mutational burden (TMB) tumors were likely to show greater responses [22]. However, another study reported a partial response even in low-TMB RCC [23]. This suggests the importance of the mutation type in addition to the number, as RCC frequently contains indel mutations (DNA insertion and deletion), which produce frameshift and variety of neo-antigens [23]. Future studies are needed to measure and evaluate the type and number of mutation, which affect the efficacy.

A phase II study evaluated the effect of pembrolizumab (NCT01876511) in colorectal cancer with deficiency of DNA mismatch repair (MMR) ability (dMMR), those with functional MMR protein expression, and all solid tumors with dMMR. Therapeutic efficacy was low in colorectal cancer with MMR protein expression, but was high in all solid tumors with dMMR [24]. Whole-exome sequencing 
showed that the average number of somatic mutations per tumor with dMMR and tumors with functional MMR (1782 and 73 , respectively) was significantly correlated with therapeutic effect. Moreover, the number of neoantigen-specific $\mathrm{T}$ cells in responding patients was significantly higher than that in non-responders in the NCT01876511 study. Accordingly, the FDA approved pembrolizumab in May 2017 for unresectable/metastatic solid cancers with high microsatellite instability (MSI-H) or dMMR in adults and children. Furthermore, the FDA approved nivolumab and the combination of nivolumab and ipilimumab in August 2017 and in July 2018, respectively, for MSI-H or dMMR metastatic colorectal cancer [25]. It is the first time that a treatment has been approved based on the biomarker rather than tumor type [26].

\section{Biomarkers-immunity-related factors}

Higher numbers of tumor-infiltrating CTLs are correlated with better prognosis. This is known as the "immunoscore" $[27,28]$, in which $\mathrm{CD}^{+} \mathrm{T}$ cell quantification at the tumor center and periphery can strongly predict the overall survival (OS) and well correlated with the traditional tumor-nodemetastasis (TNM) staging and/or MSI status in patients with colorectal cancer [28-30]. Moreover, the number of $\mathrm{CD} 8^{+} \mathrm{T}$ cells around the tumor was correlated with therapeutic effect in PD-1 antibody-treated patients with malignant melanoma treated [16]. The number of infiltrated $\mathrm{CD} 8^{+} \mathrm{T}$ cells was also correlated with high PD-L1 expression in tumor cells and the therapeutic effect of PD-1 antibodies [31]. However, the immunoscore is not a perfect marker as the significance of CTL tumor infiltration may vary depending on the type of carcinoma. For instance, in the case of RCC, higher numbers of tumor-infiltrating $\mathrm{CD} 8^{+} \mathrm{T}$ cells are correlated with poor prognosis [32].

Since tumor tissue biopsy may be extremely invasive, the use of less invasive biomarkers, such as those in peripheral blood, would represent an ideal approach. High neutrophil/ lymphocyte ratio (NLR), which is typically measured in conventional blood tests, is associated with poor prognosis in cytotoxic T lymphocyte antigen-4 (CTLA-4) antibodytreated patients with malignant melanoma [33] and in PD-1 antibody-treated patients with various cancer $[34,35]$. CD4 ${ }^{+}$ $\mathrm{T}$ cells increase in the periphery is reported to be related to good response after nivolumab treatment $[36,37]$. Cells release extracellular exosomes containing their surface molecules $[38,39]$. While an increase in circulating exosomal PD-L1 in the blood before anti-PD-1antibody treatment was associated with poor response in patients with melanoma [38], increased PD-1 and CD28 expression in exosomes, which may be derived from $\mathrm{T}$ cells, was associated with improved progression-free survival (PFS) in anti-CTLA4treated patients [40]. Instead of many ongoing researches, no peripheral blood biomarker for immune-related factors has been approved by the FDA for clinical use.

\section{Biomarkers-microbiota}

More than 1000 microorganism species and 100 trillion bacteria coexist in the human body. The maturation and barrier function of the immune system were significantly impaired in germ-free and antibiotic-treated mice. This immune impairment is normalized by transplanting mouse intestinal bacteria. The intestinal microbiota produces metabolites (such as short-chain fatty acids) from indigestible polysaccharides. The short-chain fatty acid butyric acid regulates immunity and metabolism by binding to G-protein-coupled receptors and promoting epigenome modifications [41]. A significant correlation between PD-1 blocking treatment efficacy and enterobacteria (i.e., Bifidobacterium) levels was reported in a mouse model of melanoma B 16 cells, suggesting the potential of microbiota composition as a predictive biomarker for PD-1 blockade therapy [42].

Routy et al. reported the effects of antibiotics on the response to immune checkpoint inhibitors in patients with NSCLC, RCC, and urothelial carcinoma [43]. PFS and OS significantly decreased after PD-1/PD-L1 antibody treatment in patients with a history of antibiotic treatment compared to those in patients without. Intestinal microbiota damage caused by antibiotics may therefore attenuate the anti-tumor immune response to immune checkpoint inhibitors. Moreover, intestinal microbiota composition differed between PD-1 antibody treatment responders and non-responders, and patients with a high proportion of Akkermansia muciniphila species in their microbiome showed better treatment outcomes. A significant correlation between type $1 \mathrm{~T}$ helper (Th1) responses to bacteria and treatment outcome has also been demonstrated [43]. Gopalakrishnan et al. and Matoson et al. investigated intestinal microbiota composition in PD-1 antibody-treated patients and found a significant correlation between enterobacteria diversity and responsiveness to treatment $[44,45]$. Furthermore, a recent study reported that 11 types of enterobacteria isolated from healthy individuals' feces led to $\mathrm{CD}^{+} \mathrm{T}$ cell activation, and that mice inoculated with these bacteria species showed greater tolerance to infection and anti-cancer immune responses [46]. Overall, studying crosstalk between the intestinal microbiome and the immune system would be useful for both potential biomarker candidate discovery and effective combination therapy development. 


\section{Side effects}

Immune checkpoint inhibitors may cause fewer adverse events than conventional chemotherapy (Table 1) [10, 4749]. It is of note that PD-1 antibodies generate less severe side effects than CTLA-4 antibodies [50, 51]. Combination therapy with PD-1 antibodies and chemotherapy showed side effects similar to those of chemotherapy alone, whereas combination therapy with PD- 1 and CTLA-4 antibodies may cause side effects more severe than those associated with either monotherapy (Table 1) [51-53]. Immune checkpoint inhibitor treatment requires precautions because of potential immune-related adverse events (irAEs), which differ from the adverse events observed during conventional chemotherapy. irAEs include rash with itching, diarrhea, enteritis, hepatitis, hypophysitis, thyroiditis, pneumonitis, type 1 diabetes, myositis, peripheral neuritis, and myasthenia gravis. Although many of the side effects are mild, reversible, and easy to treat, it is important to be aware of potential sever irAEs and corresponding treatment.
Treatment for irAEs relies on diagnosis to exclude noninflammatory diseases, followed by a treatment to reduce symptoms, steroid treatments, or administration of the anti-tumor necrosis factor (TNF)- $\alpha$ antibody infliximab depending on symptom severity [10,54].

Although most side effects are not severe, they often include asymptomatic endocrine consequences. Early detection and intervention are essential to reduce the risk of irAE-related side effects. Steroid treatment for irAEs has been reported to improve symptoms, although in some cases, anti-tumor immunity persists $[55,56]$, perhaps because of stronger immune responses to cancer antigens than to autoantigens. Therefore, in certain patients steroids do not sufficiently suppress immune responses to tumors, but is enough to inhibit autoimmune responses. Further studies are required to monitor autoimmune responses without impairing anti-tumor immunity and develop biomarkers that predict fatal side effects.

Table 1 Grade 3-5 adverse event related with treatment in phase III clinical trials of PD-1 antibody

\begin{tabular}{|c|c|c|c|c|}
\hline Clinical study & Tumor & Drugs & Cases & $\begin{array}{l}\text { Incidence of grade } 3-5 \text { adverse } \\
\text { event related with treatment }(\%)\end{array}$ \\
\hline \multirow[t]{2}{*}{ CheckMate 066 [10] } & \multirow{2}{*}{$\begin{array}{l}\text { Untreated metastatic melanoma without } \\
\text { BRAF mutations }\end{array}$} & Nivolumab & 206 & 11.7 \\
\hline & & Dacarbazine & 205 & 17.6 \\
\hline \multirow[t]{3}{*}{ KEYNOTE-006 [50] } & \multirow[t]{3}{*}{ Advanced melanoma } & Pembrolizumab every 2 week & 278 & 13.3 \\
\hline & & Pembrolizumab every 3 week & 277 & 10.1 \\
\hline & & Ipilimumab & 256 & 19.9 \\
\hline \multirow[t]{3}{*}{ CheckMate 067 [51] } & \multirow[t]{3}{*}{ Untreated stage III or IV melanoma } & Nivolumab alone & 313 & 16.3 \\
\hline & & Ipilimumab alone & 311 & 27.3 \\
\hline & & Nivolumab plus ipilimumab & 313 & 55.0 \\
\hline \multirow[t]{2}{*}{ CheckMate 017 [47] } & \multirow[t]{2}{*}{ Advanced squamous-cell NSCLC } & Nivolumab & 131 & 7 \\
\hline & & Docetaxel & 129 & 55 \\
\hline \multirow[t]{2}{*}{ CheckMate 057 [48] } & \multirow[t]{2}{*}{ Advanced non-squamous NSCLC } & Nivolumab & 287 & 10 \\
\hline & & Docetaxel & 268 & 54 \\
\hline \multirow[t]{3}{*}{ KEYNOTE-189 [49] } & \multirow{3}{*}{$\begin{array}{l}\text { Previously treated NSCLC with PD-L1 } \\
\text { expression on at least } 1 \% \text { of tumor cells }\end{array}$} & Pembrolizumab $2 \mathrm{mg} / \mathrm{kg}$ & 339 & 13 \\
\hline & & Pembrolizumab $10 \mathrm{mg} / \mathrm{kg}$ & 343 & 16 \\
\hline & & Docetaxel & 309 & 35 \\
\hline \multirow[t]{2}{*}{ KEYNOTE-189 [52] } & \multirow{2}{*}{$\begin{array}{l}\text { Metastatic non-squamous NSCLC with- } \\
\text { out sensitizing EGFR or ALK mutations }\end{array}$} & Pembrolizumab plus chemotherapy ${ }^{b}$ & 410 & 67.2 \\
\hline & & Chemotherapy $^{\mathrm{b}}$ & 206 & 65.8 \\
\hline \multirow[t]{2}{*}{ KEYNOTE-407 [53] } & \multirow{2}{*}{$\begin{array}{l}\text { Untreated metastatic, squamous-cell } \\
\text { NSCLC cancer }\end{array}$} & Pembrolizumab plus chemotherapy ${ }^{\mathrm{c}}$ & 278 & 69.8 \\
\hline & & Chemotherapy $^{\mathrm{c}}$ & 281 & 68.2 \\
\hline
\end{tabular}

$N S C L C$ non-small cell lung cancer, $P D-L 1$ programmed cell death ligand 1

${ }^{a}$ Original sources are given as reference numbers

${ }^{b}$ Four cycles of the investigator's choice of intravenously administered cisplatin $75 \mathrm{mg} / \mathrm{m}^{2}$ or carboplatin (area under the concentration-time curve, $5 \mathrm{mg} / \mathrm{mL} / \mathrm{min}$ ) plus pemetrexed $\left(500 \mathrm{mg} / \mathrm{m}^{2}\right)$, all administered intravenously every 3 weeks, followed by pemetrexed $500 \mathrm{mg} / \mathrm{m}^{2}$ every 3 weeks

${ }^{\mathrm{c}}$ Carboplatin (at a dose calculated to obtain an area under the concentration-time curve of $6 \mathrm{mg} / \mathrm{mL} / \mathrm{min}$ ) on day 1 and either paclitaxel $200 \mathrm{mg} /$ $\mathrm{m}^{2}$ on day 1 or nab-paclitaxel $100 \mathrm{mg} / \mathrm{m}^{2}$ on days 1,8 , and 15 


\section{Tolerance to PD-1 blockade therapy}

Although PD-1/PD-L1-blocking antibodies have longer therapeutic effects than conventional chemotherapy, resistance may occur. Zaretsky et al. analyzed biopsy specimens from four patients who first experienced tumor reduction prior to progression several years after pembrolizumab treatment. Whole-exome sequencing was performed on pairs of biopsy specimens before and after the treatment and revealed interferon receptor-related Janus kinase (JAK)1/JAK2 mutations in two of four patients, as well as mutations of histocompatibility complex (MHC) class I expression in another patient [57]. Shin et al. showed that malignant melanoma and dMMR colorectal cancer with JAK1/JAK2 mutations led to initial pembrolizumab treatment resistance despite the high number of somatic mutations. In the study, they demonstrated that JAK function loss, which inactivates the interferon signaling pathway, is involved in the impairment of antigen presentation in tumor cells [58]. Anagnostou et al. analyzed four patients with NSCLC who became refractory after receiving combination therapy with PD- 1 and CTLA- 4 antibodies. Mutation-related neoantigens were reduced in size after resistance acquisition and were involved in resistance to checkpoint inhibitors [59]. Gong et al. performed tumor gene analysis in 17 patients who had acquired tolerance to PD-L1 antibodies and identified secreted RNA splicing of PD-L1 protein variants in four patients, which competitively neutralized anti-PD-L1 antibody activity [60]. Although all analyses were performed on a relatively small sample, these findings promote the development of effective combination therapies such as immune checkpoint inhibitors.

\section{Combination therapy}

\section{Combination with chemotherapy}

The effects of typical cytotoxic anticancer drugs on antitumor immune responses are well known. Combination may improve the effect of immune checkpoint inhibitors via dendritic cell activation with increased neoantigen presentation, MHC upregulation, and inhibition of immunosuppressive cell activity [including regulator $\mathrm{T}$ cells (Tregs), M2 macrophages, and myeloid-derived suppressor cells (MDSC)] [61-63]. In the KEYNOTE-021 clinical study (phase II), patients with PD-L1-positive non-squamous NSCLC without epidermal growth factor receptor (EGFR) mutations or anaplastic lymphoma kinase (ALK) genetic translocation were tested with pembrolizumab and chemotherapy (carboplatin and pemetrexed). Patients were divided into three groups: pembrolizumab and chemotherapy group (combination therapy), maintenance therapy group, and chemotherapy only group. The response rates were $29 \%$ and $55 \%$ in the chemotherapy alone and combination therapy groups, respectively. Accordingly, the FDA approved combination therapy with pembrolizumab and chemotherapy for NSCLC in May 2017. In the KEYNOTE-189 and KEYNOTE-407 studies (phase III), PFS and OS were significantly longer in patients treated with pembrolizumab and chemotherapy than that in patients treated with chemotherapy alone. The FDA therefore extended indications for pembrolizumab and chemotherapy combination therapy [52, 53]. Moreover, the IMpower150 study (phase III) showed that PFS was longer in the combination therapy group (with chemotherapy/angiogenesis inhibitor bevacizumab), resulting in FDA approval for NSCLC in December 2018 [64]. In the IMpower133 study (phase III), atezolizumab and chemotherapy (carboplatin and etoposide) significantly prolonged both PFS and OS in patients with extensive stage small cell lung cancer, resulting in FDA approval of this combination as first-line therapy in March 2019 [65]. In addition, in the IMpassion130 study (phase III), atezolizumab and albumin-bound paclitaxel resulted in significantly longer PFS than that in the chemotherapy only group, leading to FDA approval for TNBC in March 2019 [12]. It is well known that angiogenesis supports the tumor growth. Vascular endothelial growth factor (VEGF) inhibitor inhibits the tumor growth by attenuating the angiogenesis or normalized aberrant vessel structure [66]. It is noticeable that VEGF receptor tyrosine kinase inhibitor, Axitinib combined with PD-1 blockade has improved the survival of patients with advanced renal-cell carcinoma and approved by FDA though the precise mechanisms remains unknown $[67,68]$.

Overall, these clinical studies support the enhanced efficacy of combination therapy with chemotherapy and immune checkpoint inhibitors. Considering that monotherapy with immune checkpoint inhibitors also showed significant therapeutic effects in a substantial subset of patients, the development of novel biomarkers is necessary to distinguish patients requiring only monotherapy from those requiring combination therapy.

\section{Combination with CTLA-4 antibodies}

Other immune checkpoint molecules, such as CTLA-4, T cell immunoglobulin mucin 3 (Tim3), and lymphocyte activation gene 3 (LAG3), function as immune brakes and blocking antibodies for these molecules are therefore called immune checkpoint inhibitors. CTLA-4 antibodies were first developed in the 1990s [69]. A clinical trial 
reported that patients treated with the CTLA- 4 antibody ipilimumab showed good treatment outcomes. In 2011, the FDA approved CTLA-4 antibodies as therapeutic agents for malignant melanoma. Combining the therapeutic effects of PD-1 and CTLA-4 blockade appears logical because of their different targets and mechanisms of action. Dendritic cells activate CTLs by presenting tumor antigens in lymph nodes, leading to the elimination of cancer cells expressing the same antigens. In the early phase of T cell priming, CD28 located on T cells were bound to B7 (CD80 and CD86) on dendritic cells in addition to the interaction between $\mathrm{T}$ cell receptor and MHC. CTLs prevent excess activation via the $\mathrm{B} 7$ receptor CTLA4, which binds to B7 with approximately 20 times more affinity than CD28, resulting in the CD28 signal blockade. CTLA-4 antibodies recover T cell activation by blocking the competition with CD28 [70]. CTLA-4 antibodies enhance anti-tumor activity by suppressing Treg activity or reducing the number of Tregs in the tumor tissue via antibody-dependent cellular cytotoxicity (ADCC) due to CTLA-4 overexpression on Tregs [71-73]. However, precise mechanisms remain unclear.

In the CheckMate 069 (phase II) and CheckMate 067 (phase III) studies for malignant melanoma patients, combination therapy with ipilimumab (human CTLA-4 antibody) and nivolumab significantly prolonged PFS compared with each alone, resulting in FDA approval of this combination therapy [51,74]. However, the incidence of irAEs was relatively high (Table 1). The long-term follow-up data in the CheckMate-067 study revealed that the frequency of the patients who required discontinuation of the therapy due to severe irAEs was $30 \%, 8 \%$, and $40 \%$ in the ipilimumabnivolumab combination therapy, nivolumab treatment, and ipilimumab treatment, respectively. Moreover, the incidence of side effects of $\geq$ grade 3 was $59 \%, 21 \%$, and $28 \%$, respectively [75]. In the CheckMate 214 study (phase III) of RCC, which compared combination therapy with ipilimumabnivolumab and standard treatment, the combination therapy group showed significantly longer OS and higher response rate [76]. However, certain patients in the sunitinib group who were classified as patients with "favorable risk" (good prognosis) according to the International Metastatic Renal Cell Carcinoma Database Consortium (IMDC) risk classification showed better outcomes than patients with the combination therapy. Therefore, in April 2018, the FDA approved combination therapy with ipilimumab and nivolumab for intermediate-/poor-risk patients (poor prognosis) in IMDC classification with untreated advanced RCC [76].

The efficacy of combination therapy with ipilimumab and nivolumab in patients with NSCLC was confirmed by the CheckMate-227 study [77]. In this study including patients with high TMB, the ipilimumab-nivolumab combination therapy group showed significantly longer PFS than the standard treatment group [77]. Treatment with a combination of PD- 1 and CTLA- 4 antibodies shows promise if irAEs are well controlled and if predictive biomarkers for irAEs are developed.

\section{Improvement of cancer immunotherapy via metabolic control}

Mitochondria play a central role in energy metabolism. Mitochondria-based lipid metabolism and oxidative phosphorylation are considered crucial in the formation and maintenance of memory $\mathrm{T}(\mathrm{Tm})$ cells [78]. Buck et al. reported that mitochondrial morphological changes led to metabolic reprogramming, thereby controlling $\mathrm{T}$ cell differentiation. Effector $\mathrm{T}$ (Te) cells showed small, distinct mitochondria widely dispersed in the cytoplast whereas $\mathrm{Tm}$ cells had densely fused mitochondria. Moreover, forced expression of Opa1, a gene required for mitochondrial fusion, induced Tm cell differentiation, suggesting that mitochondrial metabolism determines T cell differentiation [79]. We showed that mitochondrial activation in tumor-reactive CTLs during PD-1-blocking antibody therapy increased mitochondrial production of reactive oxygen species (ROS) [80]. Furthermore, medication promoting ROS production and metabolism-related substances activating mitochondria enhanced PD-1 blockade cancer immunotherapy. In these models, mammalian target of rapamycin (mTOR) and 5' adenosine monophosphate-activated protein kinase (AMPK) were both activated in tumor-reactive T cells, and the activation of these related signals by low-molecular weight compounds increased the therapeutic efficacy of PD-1-blocking antibody therapy (Fig. 3). Importantly, peroxisome proliferator-activated receptor (PPAR) gamma coactivator- $1 \alpha$

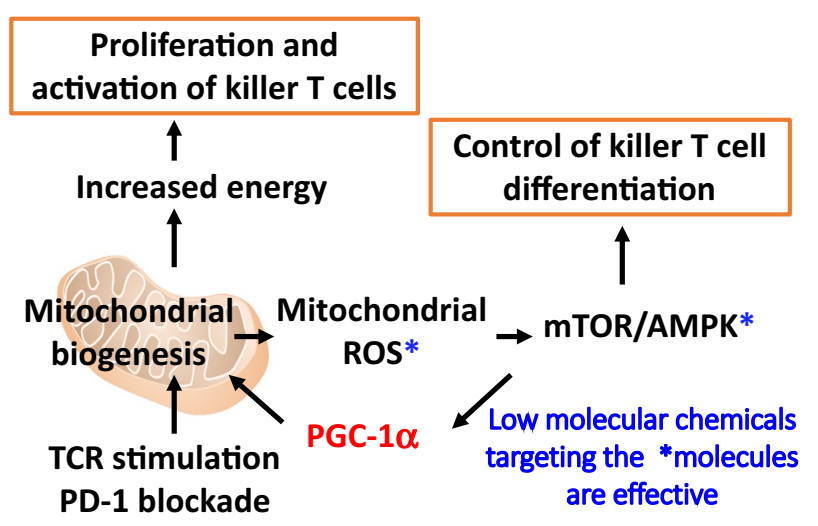

Fig. 3 Low-molecular weight drugs activating reactive oxygen species (ROS) production mTOR/AMPK, or PPAR gamma coactivator$1 \alpha$ (PGC-1 $\alpha$ ) signaling pathways enhance anti-tumor immunity mediated by PD-1 blockade 
(PGC-1 $\alpha$ )/PPAR signals, which promote mitochondrial activation, were also activated in the downstream. Tumor inhibitory effects were therefore enhanced by the combination treatment with bezafibrate, a PGC- $1 \alpha /$ PPAR complex ligand, which has been used for the treatment of hyperlipidemia in the clinic (Fig. 3) [80]. Additionally, a significant increase in total energy metabolism (mitochondrial metabolism and glycolysis) via PGC- $1 \alpha$ /PPAR signaling was observed in the $\mathrm{T}$ cells of mice receiving combination therapy with bezafibrate and PD-1-blocking antibodies. PGC- $1 \alpha /$ PPAR signaling induced high expression of carnitine palmitoyltransferase 1a (Cpt1a, a fatty acid oxidation-related gene) and B-cell lymphoma 2 (Bcl-2, an apoptosis inhibitory gene), which prevent $\mathrm{T}$ cells from activation-induced apoptosis [81]. These systems may convert tumor-reactive Te cells, which are supposed to be short-lived, into long-surviving Te cells, resulting in an overall increase of Te numbers and thus enhancing therapeutic efficacy. Scharping et al. reported low PGC-1 $\alpha$ expression levels in exhausted T cells within a tumor microenvironment, although forced PGC- $1 \alpha$ expression in $\mathrm{T}$ cells rescued cells from a state of exhaustion via mitochondrial-related metabolic reprogramming and enhanced tumor inhibition [82]. Anti-tumor responses may therefore be improved by energy metabolism control via the mitochondria in $\mathrm{T}$ cells. The authors also investigated differences in the ability to induce a hypoxic tumor microenvironment, which regulates responsiveness to immune checkpoint inhibitors, in a mouse model. Metformin, which is used to treat type 2 diabetes, suppressed intratumoral oxygen consumption by tumor cells in vitro and in vivo, reduced the intratumoral hypoxic state, and improved intratumoral $\mathrm{T}$ cell function, when used in combination with PD-1 antibodies [83]. Bezafibrate and metformin cause fewer side effects and have been used to treat other diseases, suggesting the greater feasibility of combination therapy with these drugs and cancer immunotherapy.

\section{Future perspectives}

PD-1 antibodies have been rapidly developed after their introduction into cancer immunotherapy. However, treatment efficacy varies widely according to cancer type, and treatment cannot be applied uniformly even to patients with the same cancer type. Overall, many challenges remain in the context of PD-1 antibody treatment. Further improvement in cancer care relies on: (1) elucidation of the fundamental mechanisms explaining how PD-1 antibodies possess anti-tumor effects, (2) biomarker development for better prediction of therapeutic and side effects, and (3) the development of combination therapy with fewer side effects. Novel findings and strategies addressing the three issues mentioned here would ensure the improvement of cancer immunotherapy.

Acknowledgements This work was supported by AMED (Grant numbers 18cm0106302h0003, T. Honjo; 18lk1403006h0002, K. Chamoto), the Tang Prize Foundation (T. Honjo), JSPS KAKENHI (Grant numbers JP16H06149 and 17K19593, K. Chamoto; 19K17673, R. Hatae), and the Cell Science Foundation (K. Chamoto). We also thank BristolMyers Squibb for their collaboration.

\section{Compliance with ethical standards}

Conflict of interest The authors declare no potential conflicts of interest.

Open Access This article is distributed under the terms of the Creative Commons Attribution 4.0 International License (http://creativeco mmons.org/licenses/by/4.0/), which permits unrestricted use, distribution, and reproduction in any medium, provided you give appropriate credit to the original author(s) and the source, provide a link to the Creative Commons license, and indicate if changes were made.

\section{References}

1. Dunn GP, Bruce AT, Ikeda $\mathrm{H}$ et al (2002) Cancer immunoediting: from immunosurveillance to tumor escape. Nat Immunol 3(11):991-998. https://doi.org/10.1038/ni1102-991

2. Ishida Y, Agata Y, Shibahara K et al (1992) Induced expression of PD-1, a novel member of the immunoglobulin gene superfamily, upon programmed cell death. EMBO J 11(11):3887-3895

3. Nishimura H, Nose M, Hiai H et al (1999) Development of lupus-like autoimmune diseases by disruption of the PD-1 gene encoding an ITIM motif-carrying immunoreceptor. Immunity 11(2):141-151

4. Nishimura H, Okazaki T, Tanaka Y et al (2001) Autoimmune dilated cardiomyopathy in PD-1 receptor-deficient mice. Science 291(5502):319-322. https://doi.org/10.1126/scien ce. 291.5502 .319

5. Wang J, Yoshida T, Nakaki F et al (2005) Establishment of NODPdcd1-/- mice as an efficient animal model of type I diabetes. Proc Natl Acad Sci USA 102(33):11823-11828. https://doi. org/10.1073/pnas.0505497102

6. Okazaki T, Honjo T (2007) PD-1 and PD-1 ligands: from discovery to clinical application. Int Immunol 19(7):813-824. https:// doi.org/10.1093/intimm/dxm057

7. Iwai Y, Ishida M, Tanaka Y et al (2002) Involvement of PD-L1 on tumor cells in the escape from host immune system and tumor immunotherapy by PD-L1 blockade. Proc Natl Acad Sci USA 99(19):12293-12297. https://doi.org/10.1073/pnas.192461099

8. Brahmer JR, Drake CG, Wollner I et al (2010) Phase I study of single-agent anti-programmed death-1 (MDX-1106) in refractory solid tumors: safety, clinical activity, pharmacodynamics, and immunologic correlates. J Clin Oncol 28(19):3167-3175. https ://doi.org/10.1200/JCO.2009.26.7609

9. Topalian SL, Hodi FS, Brahmer JR et al (2012) Safety, activity, and immune correlates of anti-PD-1 antibody in cancer. N Engl J Med 366(26):2443-2454. https://doi.org/10.1056/NEJMoa1200 690

10. Robert C, Long GV, Brady B et al (2015) Nivolumab in previously untreated melanoma without BRAF mutation. N Engl J Med 372(4):320-330. https://doi.org/10.1056/NEJMoa1412082 
11. Motzer RJ, Escudier B, McDermott DF et al (2015) Nivolumab versus everolimus in advanced renal-cell carcinoma. N Engl J Med 373(19):1803-1813. https://doi.org/10.1056/NEJMoa1510665

12. Schmid P, Adams S, Rugo HS et al (2018) Atezolizumab and nabpaclitaxel in advanced triple-negative breast cancer. N Engl J Med 379(22):2108-2121. https://doi.org/10.1056/NEJMoa1809615

13. Kataoka K, Shiraishi Y, Takeda Y et al (2016) Aberrant PD-L1 expression through 3'-UTR disruption in multiple cancers. Nature 534(7607):402-406. https://doi.org/10.1038/nature18294

14. Mahoney KM, Atkins MB (2014) Prognostic and predictive markers for the new immunotherapies. Oncology (Williston Park) 28(Suppl 3):39-48

15. Taube JM, Anders RA, Young GD et al (2012) Colocalization of inflammatory response with B7-h1 expression in human melanocytic lesions supports an adaptive resistance mechanism of immune escape. Sci Transl Med 4(127):127. https://doi. org/10.1126/scitranslmed.3003689

16. Tumeh PC, Harview CL, Yearley JH et al (2014) PD-1 blockade induces responses by inhibiting adaptive immune resistance. Nature 515(7528):568-571. https://doi.org/10.1038/nature13954

17. Herbst RS, Soria JC, Kowanetz M et al (2014) Predictive correlates of response to the anti-PD-L1 antibody MPDL3280A in cancer patients. Nature 515(7528):563-567. https://doi.org/10.1038/ nature 14011

18. Powles T, Eder JP, Fine GD et al (2014) MPDL3280A (antiPD-L1) treatment leads to clinical activity in metastatic bladder cancer. Nature 515(7528):558-562. https://doi.org/10.1038/natur e13904

19. Lin H, Wei S, Hurt EM et al (2018) Host expression of PD-L1 determines efficacy of PD-L1 pathway blockade-mediated tumor regression. J Clin Invest 128(2):805-815. https://doi.org/10.1172/ JCI96113

20. Alexandrov LB, Nik-Zainal S, Wedge DC et al (2013) Signatures of mutational processes in human cancer. Nature 500(7463):415421. https://doi.org/10.1038/nature12477

21. Rizvi NA, Hellmann MD, Snyder A et al (2015) Cancer immunology Mutational landscape determines sensitivity to PD-1 blockade in non-small cell lung cancer. Science 348(6230):124-128. https ://doi.org/10.1126/science.aaa1348

22. Carbone DP, Reck M, Paz-Ares L et al (2017) First-line nivolumab in stage IV or recurrent non-small-cell lung cancer. N Engl J Med 376(25):2415-2426. https://doi.org/10.1056/NEJMoa1613493

23. Turajlic S, Litchfield K, Xu H et al (2017) Insertion-and-deletionderived tumour-specific neoantigens and the immunogenic phenotype: a pan-cancer analysis. Lancet Oncol 18(8):1009-1021. https ://doi.org/10.1016/S1470-2045(17)30516-8

24. Le DT, Uram JN, Wang H et al (2015) PD-1 blockade in tumors with mismatch-repair deficiency. N Engl J Med 372(26):25092520. https://doi.org/10.1056/NEJMoa1500596

25. Overman MJ, Lonardi S, Wong KYM et al (2018) Durable clinical benefit with nivolumab plus ipilimumab in dna mismatch repairdeficient/microsatellite instability-high metastatic colorectal cancer. J Clin Oncol 36(8):773-779. https://doi.org/10.1200/ JCO.2017.76.9901

26. Le DT, Durham JN, Smith KN et al (2017) Mismatch repair deficiency predicts response of solid tumors to PD-1 blockade. Science 357(6349):409-413. https://doi.org/10.1126/science.aan67 33

27. Fridman WH, Pages F, Sautes-Fridman C et al (2012) The immune contexture in human tumours: impact on clinical outcome. Nat Rev Cancer 12(4):298-306. https://doi.org/10.1038/ $\operatorname{nrc} 3245$

28. Galon J, Costes A, Sanchez-Cabo F et al (2006) Type, density, and location of immune cells within human colorectal tumors predict clinical outcome. Science 313(5795):1960-1964. https:// doi.org/10.1126/science.1129139

29. Mlecnik B, Bindea G, Angell HK et al (2016) Integrative analyses of colorectal cancer show immunoscore is a stronger predictor of patient survival than microsatellite instability. Immunity 44(3):698-711. https://doi.org/10.1016/j.immuni.2016.02.025

30. Pages F, Mlecnik B, Marliot F et al (2018) International validation of the consensus immunoscore for the classification of colon cancer: a prognostic and accuracy study. Lancet 391(10135):21282139. https://doi.org/10.1016/S0140-6736(18)30789-X

31. Thommen DS, Koelzer VH, Herzig P et al (2018) A transcriptionally and functionally distinct PD-1(+) CD8(+) T cell pool with predictive potential in non-small-cell lung cancer treated with PD-1 blockade. Nat Med 24(7):994-1004. https://doi.org/10.1038/ s41591-018-0057-z

32. Giraldo NA, Becht E, Pages F et al (2015) Orchestration and prognostic significance of immune checkpoints in the microenvironment of primary and metastatic renal cell cancer. Clin Cancer Res 21(13):3031-3040. https://doi.org/10.1158/1078-0432. CCR-14-2926

33. Ferrucci PF, Ascierto PA, Pigozzo J et al (2016) Baseline neutrophils and derived neutrophil-to-lymphocyte ratio: prognostic relevance in metastatic melanoma patients receiving ipilimumab. Ann Oncol 27(4):732-738. https://doi.org/10.1093/annonc/mdw016

34. Nakamura Y, Kitano S, Takahashi A et al. (2016) Nivolumab for advanced melanoma: pretreatment prognostic factors and early outcome markers during therapy. Oncotarget 7(47): 77404-77415. 10.18632/oncotarget.12677.

35. Bagley SJ, Kothari S, Aggarwal C et al (2017) Pretreatment neutrophil-to-lymphocyte ratio as a marker of outcomes in nivolumab-treated patients with advanced non-small-cell lung cancer. Lung Cancer 106:1-7. https://doi.org/10.1016/j.lungc an.2017.01.013

36. Takeuchi Y, Tanemura A, Tada Y et al (2018) Clinical response to PD-1 blockade correlates with a sub-fraction of peripheral central memory CD4+ T cells in patients with malignant melanoma. Int Immunol 30(1):13-22. https://doi.org/10.1093/intimm/dxx073

37. Manjarrez-Orduno N, Menard LC, Kansal S et al (2018) Circulating T cell subpopulations correlate with immune responses at the tumor site and clinical response to PD1 inhibition in non-small cell lung Cancer. Front Immunol 9:1613. https://doi.org/10.3389/ fimmu.2018.01613

38. Chen G, Huang AC, Zhang W et al (2018) Exosomal PD-L1 contributes to immunosuppression and is associated with anti-PD-1 response. Nature 560(7718):382-386. https://doi.org/10.1038/ s41586-018-0392-8

39. Yang Y, Li CW, Chan LC et al (2018) Exosomal PD-L1 harbors active defense function to suppress $\mathrm{T}$ cell killing of breast cancer cells and promote tumor growth. Cell Res 28(8):862-864. https ://doi.org/10.1038/s41422-018-0060-4

40. Tucci M, Passarelli A, Mannavola F et al (2018) Serum exosomes as predictors of clinical response to ipilimumab in metastatic melanoma. Oncoimmunology 7(2):e1387706. https://doi. org/10.1080/2162402X.2017.1387706

41. Lee WJ, Hase K (2014) Gut microbiota-generated metabolites in animal health and disease. Nat Chem Biol 10(6):416-424. https ://doi.org/10.1038/nchembio.1535

42. Sivan A, Corrales L, Hubert N et al (2015) Commensal bifidobacterium promotes antitumor immunity and facilitates anti-PD-L1 efficacy. Science 350(6264):1084-1089. https://doi.org/10.1126/ science.aac 4255

43. Routy B, Le Chatelier E, Derosa L et al (2018) Gut microbiome influences efficacy of PD-1-based immunotherapy against epithelial tumors. Science 359(6371):91-97. https://doi.org/10.1126/ science.aan 3706 
44. Gopalakrishnan V, Spencer CN, Nezi L et al (2018) Gut microbiome modulates response to anti-PD-1 immunotherapy in melanoma patients. Science 359(6371):97-103. https://doi. org/10.1126/science.aan4236

45. Matson V, Fessler J, Bao R et al (2018) The commensal microbiome is associated with anti-PD-1 efficacy in metastatic melanoma patients. Science 359(6371):104-108. https://doi.org/10.1126/ science.aao3290

46. Tanoue T, Morita S, Plichta DR et al (2019) A defined commensal consortium elicits CD8 T cells and anti-cancer immunity. Nature 565(7741):600-605. https://doi.org/10.1038/s41586-019-0878-Z

47. Brahmer J, Reckamp KL, Baas P et al (2015) Nivolumab versus docetaxel in advanced squamous-cell non-small-cell lung cancer. N Engl J Med 373(2):123-135. https://doi.org/10.1056/NEJMo a1504627

48. Borghaei H, Paz-Ares L, Horn L et al (2015) Nivolumab versus docetaxel in advanced nonsquamous non-small-cell lung cancer. $\mathrm{N}$ Engl J Med 373(17):1627-1639. https://doi.org/10.1056/NEJMo a1507643

49. Herbst RS, Baas P, Kim DW et al (2016) Pembrolizumab versus docetaxel for previously treated, PD-L1-positive, advanced nonsmall-cell lung cancer (KEYNOTE-010): a randomised controlled trial. Lancet 387(10027):1540-1550. https://doi.org/10.1016/ S0140-6736(15)01281-7

50. Robert C, Schachter J, Long GV et al (2015) Pembrolizumab versus ipilimumab in advanced melanoma. $\mathrm{N}$ Engl $\mathrm{J}$ Med 372(26):2521-2532. https://doi.org/10.1056/NEJMoa1503093

51. Larkin J, Chiarion-Sileni V, Gonzalez R et al (2015) Combined nivolumab and ipilimumab or monotherapy in untreated melanoma. N Engl J Med 373(1):23-34. https://doi.org/10.1056/ NEJMoa1504030

52. Gandhi L, Rodriguez-Abreu D, Gadgeel S et al (2018) Pembrolizumab plus chemotherapy in metastatic non-small-cell lung cancer. N Engl J Med 378(22):2078-2092. https://doi.org/10.1056/ NEJMoa1801005

53. Paz-Ares L, Luft A, Vicente D et al (2018) Pembrolizumab plus chemotherapy for squamous non-small-cell lung cancer. N Engl J Med 379(21):2040-2051. https://doi.org/10.1056/NEJMoa1810 865

54. Nishino M, Ramaiya NH, Awad MM et al (2016) PD-1 inhibitorrelated pneumonitis in advanced cancer patients: radiographic patterns and clinical course. Clin Cancer Res 22(24):6051-6060. https://doi.org/10.1158/1078-0432.CCR-16-1320

55. Beck KE, Blansfield JA, Tran KQ et al (2006) Enterocolitis in patients with cancer after antibody blockade of cytotoxic T-lymphocyte-associated antigen 4. J Clin Oncol 24(15):2283-2289. https://doi.org/10.1200/JCO.2005.04.5716

56. Maker AV, Yang JC, Sherry RM et al (2006) Intrapatient dose escalation of anti-CTLA-4 antibody in patients with metastatic melanoma. J Immunother 29(4):455-463. https://doi. org/10.1097/01.cji.0000208259.73167.58

57. Zaretsky JM, Garcia-Diaz A, Shin DS et al (2016) Mutations associated with acquired resistance to PD-1 blockade in melanoma. N Engl J Med 375(9):819-829. https://doi.org/10.1056/NEJMo a1604958

58. Shin DS, Zaretsky JM, Escuin-Ordinas H et al (2017) Primary resistance to PD-1 blockade mediated by JAK1/2 mutations. Cancer Discov 7(2):188-201. https://doi.org/10.1158/2159-8290. CD-16-1223

59. Anagnostou V, Smith KN, Forde PM et al (2017) Evolution of neoantigen landscape during immune checkpoint blockade in nonsmall cell lung cancer. Cancer Discov 7(3):264-276. https://doi. org/10.1158/2159-8290.CD-16-0828

60. Gong B, Kiyotani K, Sakata S et al (2019) Secreted PD-L1 variants mediate resistance to PD-L1 blockade therapy in non-small cell lung cancer. J Exp Med 216(4):982-1000. https://doi. org/10.1084/jem.20180870

61. Bracci L, Schiavoni G, Sistigu A et al (2014) Immune-based mechanisms of cytotoxic chemotherapy: implications for the design of novel and rationale-based combined treatments against cancer. Cell Death Differ 21(1):15-25. https://doi. org/10.1038/cdd.2013.67

62. Apetoh L, Ladoire S, Coukos G et al (2015) Combining immunotherapy and anticancer agents: the right path to achieve cancer cure? Ann Oncol 26(9):1813-1823. https://doi.org/10.1093/ annonc/mdv209

63. Gotwals P, Cameron S, Cipolletta D et al (2017) Prospects for combining targeted and conventional cancer therapy with immunotherapy. Nat Rev Cancer 17(5):286-301. https://doi. org/10.1038/nrc.2017.17

64. Socinski MA, Jotte RM, Cappuzzo F et al (2018) Atezolizumab for First-line treatment of metastatic nonsquamous NSCLC. N Engl J Med 378(24):2288-2301. https://doi.org/10.1056/ NEJMoa1716948

65. Horn L, Mansfield AS, Szczesna A et al (2018) First-Line atezolizumab plus chemotherapy in extensive-stage small-cell lung cancer. N Engl J Med 379(23):2220-2229. https://doi. org/10.1056/NEJMoa1809064

66. Arjaans M, Schroder CP, Oosting SF et al (2016) VEGF pathway targeting agents, vessel normalization and tumor drug uptake: from bench to bedside. Oncotarget 7(16): 21247-21258. 10.18632/oncotarget.6918.

67. Rini BI, Plimack ER, Stus V et al (2019) Pembrolizumab plus axitinib versus sunitinib for advanced renal-cell carcinoma. N Engl J Med 380(12):1116-1127. https://doi.org/10.1056/ NEJMoa1816714

68. Motzer RJ, Penkov K, Haanen J et al (2019) Avelumab plus axitinib versus sunitinib for advanced renal-cell carcinoma. N Engl J Med 380(12):1103-1115. https://doi.org/10.1056/ NEJMoa1816047

69. Leach DR, Krummel MF, Allison JP (1996) Enhancement of antitumor immunity by CTLA-4 blockade. Science 271(5256):1734-1736

70. Ribas A (2012) Tumor immunotherapy directed at PD-1. N Engl J Med 366(26):2517-2519. https://doi.org/10.1056/NEJMe 1205943

71. Quezada SA, Simpson TR, Peggs KS et al (2010) Tumor-reactive CD4(+) T cells develop cytotoxic activity and eradicate large established melanoma after transfer into lymphopenic hosts. J Exp Med 207(3):637-650. https://doi.org/10.1084/ jem.20091918

72. Bulliard Y, Jolicoeur R, Windman M et al (2013) Activating Fc gamma receptors contribute to the antitumor activities of immunoregulatory receptor-targeting antibodies. J Exp Med 210(9):1685-1693. https://doi.org/10.1084/jem.20130573

73. Simpson TR, Li F, Montalvo-Ortiz W et al (2013) Fc-dependent depletion of tumor-infiltrating regulatory $\mathrm{T}$ cells co-defines the efficacy of anti-CTLA-4 therapy against melanoma. J Exp Med 210(9):1695-1710. https://doi.org/10.1084/jem.20130579

74. Postow MA, Chesney J, Pavlick AC et al (2015) Nivolumab and ipilimumab versus ipilimumab in untreated melanoma. N Engl J Med 372(21):2006-2017. https://doi.org/10.1056/NEJMoa1414 428

75. Wolchok JD, Chiarion-Sileni V, Gonzalez R et al (2017) Overall survival with combined nivolumab and ipilimumab in advanced melanoma. N Engl J Med 377(14):1345-1356. https://doi. org/10.1056/NEJMoa1709684

76. Motzer RJ, Tannir NM, McDermott DF et al (2018) Nivolumab plus ipilimumab versus sunitinib in advanced renal-cell carcinoma. N Engl J Med 378(14):1277-1290. https://doi. org/10.1056/NEJMoa1712126 
77. Hellmann MD, Ciuleanu TE, Pluzanski A et al (2018) Nivolumab plus ipilimumab in lung cancer with a high tumor mutational burden. N Engl J Med 378(22):2093-2104. https:// doi.org/10.1056/NEJMoa1801946

78. Pearce EL, Walsh MC, Cejas PJ et al (2009) Enhancing CD8 T-cell memory by modulating fatty acid metabolism. Nature 460(7251):103-107. https://doi.org/10.1038/nature08097

79. Buck MD, O'Sullivan D, Klein Geltink RI et al (2016) Mitochondrial Dynamics Controls T Cell Fate through Metabolic Programming. Cell 166(1):63-76. https://doi.org/10.1016/j. cell.2016.05.035

80. Chamoto K, Chowdhury PS, Kumar A et al (2017) Mitochondrial activation chemicals synergize with surface receptor PD-1 blockade for T cell-dependent antitumor activity. Proc Natl Acad Sci U S A 114(5):E761-E770. https://doi.org/10.1073/pnas.1620433114

81. Chowdhury PS, Chamoto K, Kumar A et al (2018) PPAR-induced fatty acid oxidation in $\mathrm{T}$ cells increases the number of tumorreactive $\mathrm{CD} 8(+) \mathrm{T}$ cells and facilitates anti-PD-1 therapy. Cancer
Immunol Res 6(11):1375-1387. https://doi.org/10.1158/23266066.CIR-18-0095

82. Scharping NE, Menk AV, Moreci RS et al (2016) The tumor microenvironment represses $\mathrm{T}$ cell mitochondrial biogenesis to drive intratumoral $\mathrm{T}$ cell metabolic insufficiency and dysfunction. Immunity 45(2):374-388. https://doi.org/10.1016/j.immun i.2016.07.009

83. Scharping NE, Menk AV, Whetstone RD et al (2017) Efficacy of PD-1 blockade is potentiated by metformin-induced reduction of tumor hypoxia. Cancer Immunol Res 5(1):9-16. https://doi. org/10.1158/2326-6066.CIR-16-0103

Publisher's Note Springer Nature remains neutral with regard to jurisdictional claims in published maps and institutional affiliations. 